\title{
Genetic Alterations in Gastric Adenomas of Intestinal and Foveolar Phenotypes
}

Susan C. Abraham, M.D., Seun Ja Park, M.D., Ph.D., Jae-Hyuk Lee, M.D., Ph.D., Lilian Mugartegui, B.S., Tsung-Teh Wu, M.D., Ph.D.

Department of Pathology, Mayo Clinic, Rochester, MN (SCA), and Department of Pathology, University of Texas M.D. Anderson Cancer Center, Houston, TX (SJP, JHL, LM, TTW)

Gastric adenomas are unusual neoplasms that can constitute one of the direct precursors to gastric adenocarcinoma. Most gastric adenomas are comprised of polypoid projections of dysplastic epithelium with at least focal intestinal-type differentiation (containing goblet cells and/or Paneth cells), whereas adenomas comprised entirely of dysplastic foveolar-type epithelium are rare. It has been shown that nearly all intestinal-type adenomas arise in association with background intestinal metaplasia and gastric atrophy, approximately $40 \%$ harbor high-grade dysplasia, and nearly one fourth progress to adenocarcinoma. In contrast, foveolartype adenomas tend to occur in otherwise normal, nonatrophic gastric mucosa and rarely harbor highgrade dysplasia or carcinoma. Potential differences in the genetic alterations between intestinal-type and foveolar-type gastric adenomas have not been systematically studied. We investigated 11 intestinal-type and 7 foveolar-type gastric adenomas (all from patients without familial adenomatous polyposis) for alterations in $A P C$ (using $5 q$ allelic loss assays and direct DNA sequencing of the mutation cluster region), $\beta$-catenin (using direct DNA sequencing of the phosphorylation region in exon 3), K-ras (using direct DNA sequencing of codons 12 and 13), and microsatellite instability (MSI; using fluorescent-based PCR amplification of a standard panel of 5 microsatellite markers). Overall, 10 of $11(91 \%)$ intestinal-type adenomas harbored at least one detectable genetic alteration, whereas only 3 of 7 (43\%) of foveolar-type adenomas did $(P=.047)$. However, no statistically significant differences in any particular genetic alteration were found. Among intestinal-type adenomas, $A P C$

Copyright () 2003 by The United States and Canadian Academy of Pathology, Inc.

VOL. 16, NO. 8, P. 786, 2003 Printed in the U.S.A

Date of acceptance: May 1, 2003.

Address reprint requests to: Susan C. Abraham, M.D., Department of Pathology, Hilton 11, Mayo Clinic, 200 First Street SW, Rochester, MN 55905; fax: 507-284-1599; e-mail: abraham.susan@mayo.edu.

DOI: $10.1097 / 01 . M P .0000080349 .37658 .5 E$ alterations were present in seven $(64 \%)$, high-level MSI in three $(\mathbf{2 7 \%})$, and $K$-ras mutations in two (18\%). Among foveolar-type adenomas, $A P C$ alterations were present in three $(43 \%)$ and a $K$-ras mutation in one of six amplifiable polyps (17\%). Neither APC nor MSI correlated with the size of the adenoma, but $K$-ras mutations were found only in lesions of $\geq 1 \mathrm{~cm}$. $\beta$-catenin mutations were not present in any gastric adenoma, irrespective of the presence or absence of $A P C$ alterations. These results suggest that the types and frequencies of genetic alterations occurring in gastric and colorectal adenomas are similar. Although intestinal-type and foveolar-type gastric adenomas display divergent biologic behavior, the specific genetic events accounting for these differences in morphology and biologic behavior are unclear.

KEY WORDS: Adenoma, APC, $\beta$-catenin, $K$-ras, Microsatellite instability, Stomach.

Mod Pathol 2003;16(8):786-795

Gastric adenomas are relatively infrequent neoplasms which constitute at most approximately $10 \%$ of polyps arising in the stomach in Western populations (1). Despite this, adenomas hold importance because they can serve both as a direct precursor to gastric adenocarcinoma and as a marker for increased neoplastic risk elsewhere in the stomach (2-7). Previous series have reported rates of carcinoma arising within adenomas that range from $2.5 \%$ to $>50 \%(2-7)$; in a 16 -year retrospective review of gastric adenomas examined at The Johns Hopkins Hospital, we recently found that $15 \%$ of the polyps harbored carcinoma, and $10 \%$ of patients with adenomas had carcinomas elsewhere in the stomach (8).

Although all gastric adenomas are definitionally composed of polypoid, dysplastic epithelium, the morphologic features of adenomas vary. Most are formed from dysplastic intestinal-type epithelium that is comprised of a mixture of goblet cells with intestinal mucin and gastric (foveolar-type) cells 
with neutral mucin (Fig. 1; 2, 8-10). Much less commonly, adenomas are formed entirely or predominantly from dysplastic epithelial cells that resemble gastric (foveolar-type) cells both morphologically and by mucin immunohistochemistry (Fig. $2 ; 8,9,11)$. We found that intestinal-type gastric adenomas were more likely than those of foveolartype to show high-grade dysplasia, to harbor intramucosal or invasive adenocarcinoma, and to arise in a background of extensive mucosal atrophy and intestinal metaplasia (8). A few other reports have also suggested that an intestinal versus foveolar phenotype of gastric adenomas correlates with greater malignant potential $(2,12)$.

Genetic alterations contributing to the development and neoplastic progression of gastric adenomas have been studied with respect to the adenomatous polyposis coli (APC; 13-15), K-ras $(6,13$, $15-18)$, and $p 53(6,11,13,19-24)$ genes and with respect to MSI $(15,18,23-28)$. However, only one study has separately evaluated intestinal-type and foveolar-type adenomas. In that series, Kushima et al. (11) found that p53 immunolabeling was significantly more common in intestinal-type than in gastric-type adenomas, suggesting that there might be genetic differences that underlie the phenotypic differences between these two types of lesions. In this study, we evaluate 18 gastric adenomas for differences in MSI and in APC, $\beta$-catenin, and $K$-ras gene mutations between those of intestinal and foveolar phenotypes.

\section{MATERIALS AND METHODS}

\section{Study Population}

The study population consisted of 11 intestinaltype gastric adenomas and 7 foveolar-type adenomas removed at The Johns Hopkins Hospital between 1993 and 2001. All were endoscopically polypoid lesions projecting above the adjoining gastric mucosa (i.e., no "flat" or "depressed adenomas" were included). As previously described (8), we classified adenomas with the aid of periodic acid-Schiff/Alcian blue at $\mathrm{pH} 2.5$ staining as intestinal type if there were Paneth cells or goblet cells (even focally) and as foveolar type if they were composed entirely of dysplastic foveolar cells with an apical cap of neutral mucin (Figs. 1, 2). The degree of epithelial dysplasia was categorized as either low grade or high grade according to previously published criteria (29-31). Adenoma size was

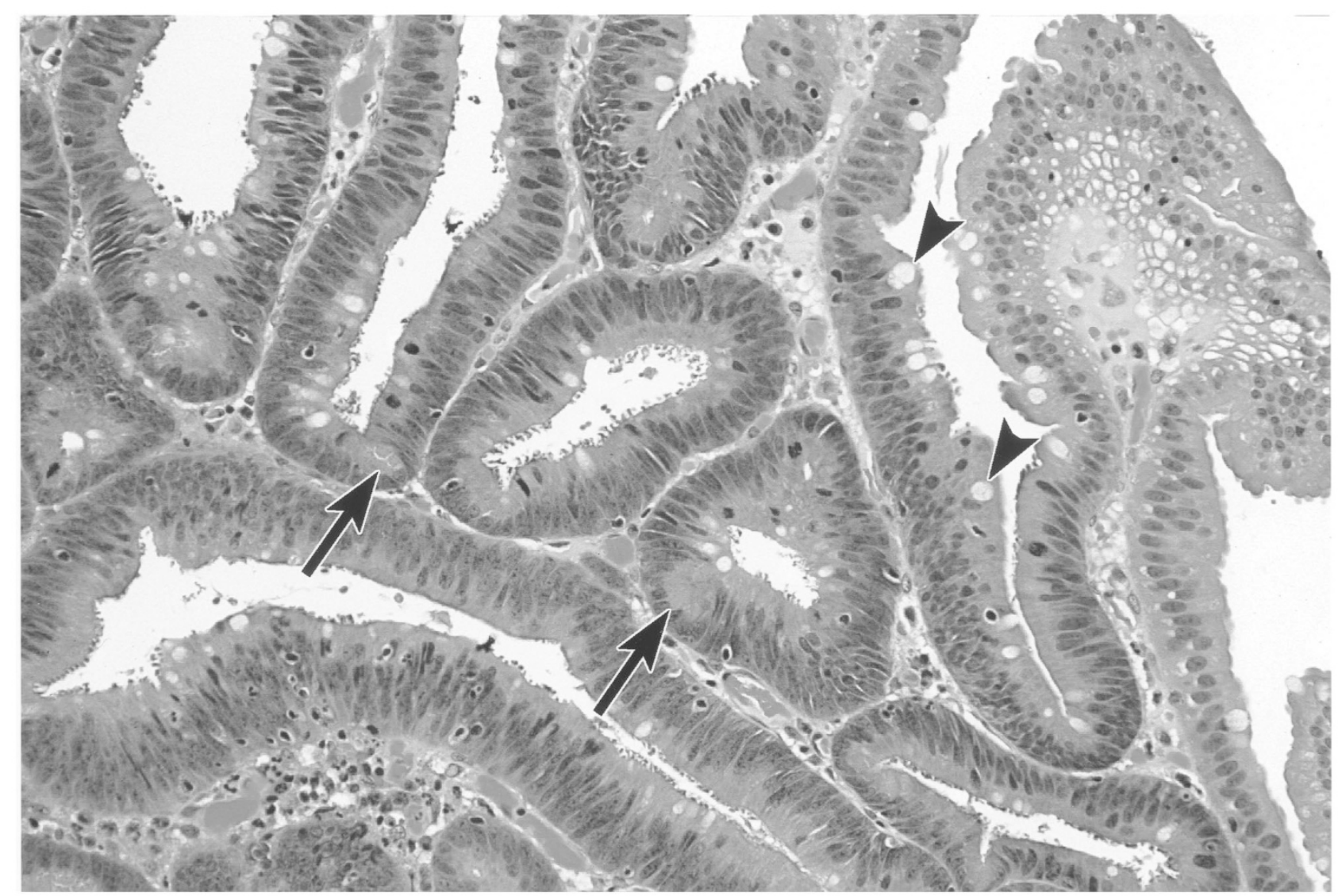

FIGURE 1. Histologic appearance of an intestinal-type gastric adenoma. Scattered goblet cells (arrowheads) and Paneth cells (arrows) are present. Epithelial dysplasia is classified as low grade in this adenoma (hematoxylin and eosin stain). 



FIGURE 2. Histologic appearance of foveolar-type gastric adenomas. A, foveolar-type adenoma with low-grade dysplasia in a patient with familial adenomatous polyposis (FAP; hematoxylin and eosin stain). B, periodic acid-Schiff/Alcian blue stain at pH 2.5 highlights the apical neutral mucin cap of the epithelial cells in this adenoma and its lack of goblet cells. C, the sporadic, non-FAP-associated foveolar-type adenomas analyzed in this study are histologically similar to FAP-associated adenomas (hematoxylin and eosin stain). D, higher power view demonstrating the presence of apical mucin caps in the lining epithelium (arrowheads). The nuclei are enlarged and crowded but show only mild pseudostratification, characteristic of low-grade dysplasia (hematoxylin and eosin stain).

obtained from either the endoscopic or gross pathology reports.

Although we have previously noted that most foveolar-type adenomas occur in patients with familial adenomatous polyposis (FAP; 8), the seven foveolar-type adenomas analyzed here were all sporadic adenomas removed from patients with no clinical indication of FAP.

\section{DNA Extraction}

Genomic DNA was obtained by microdissection of H\&E-stained slides prepared from routinely processed, formalin-fixed, paraffinembedded specimens. A 27.5-gauge needle tip was used for microdissection under a low-power, $4 \times$ objective. DNA was extracted according to protocol described elsewhere (32). Gastric adenomas were microdissected as well as normal control tissue that was obtained from nonpolypoid stomach mucosa (in 16 cases), duodenum (in 1 case), or esophagus (in 1 case).
Mutational Analysis of the APC, $\beta$-Catenin, and K-ras Genes

Direct DNA sequencing was used to evaluate for mutations in $A P C, \beta$-catenin, and $K$-ras. For $A P C$, genomic DNA was amplified by polymerase chain reaction (PCR) using four sets of overlapping oligonucleotide primers that span the mutation cluster region in exon 15 (A1: 5'-CAGACTTATTGTGTAGAAGA-3' and A2: 5'-CTCCTGAAGAAAATTCAACA-3' for codons 1260-1359; B1: 5'-AGGGTTCTAGTTTATCTTCA-3' and B2: 5'-TCTGCTTGGTGGCATGGTTT-3' for codons 1339-1436; C1: 5'-GGCATTATAAGCCCCAGTGA-3' and C2: 5'-AAATGGCTCATCGAGGCTCA-3' for codons 1417-1516; D1: 5'-ACTCCAGATGGATTTTCTTG-3' and D2: 5'-GGCTGGCTTTTTTGCTTTAC-3' for codons 1497-1596). For $\beta$-catenin, PCR was performed using a primer pair (forward: $5^{\prime}$ ATGGAACCAGACAGAAAAGC-3' and reverse: 5'GCTACTTGTTCTGAGTGAAG-3') that amplified a 200-bp fragment in exon 3 encompassing the region for glycogen synthase kinase-3 $\beta$ (GSK-3 $\beta$ ) phosphorylation and ubiquitin-mediated degradation of $\beta$-catenin protein. For $K$-ras, PCR was performed with 
a primer pair (forward: 5'-GAGAATTCATGACTGAATATAAACTTGT-3' and reverse: 5'-TCGAATTCCTCTATTGTTGGATCATATTCG-3') that amplified a region in exon 1 spanning codons 12 and 13. All PCR reactions were performed on a GeneAmp PCR System 9700 (Applied Biosystems, Foster City, CA) in 50- $\mu \mathrm{L}$ volumes that contained $2 \mu \mathrm{L}$ of genomic DNA, $10 \mathrm{~mm}$ dNTP mix, 2.25 U AmpliTaq Gold (Applied Biosystems), 0.125 U Pfu DNA Polymerase (Stratagene, La Jolla, CA), and 20 pmol of forward and reverse primers. PCR conditions for APC consisted of an initial denaturation step of $95^{\circ} \mathrm{C}$ for 10 minutes, 40 cycles $\left(94^{\circ} \mathrm{C}\right.$ for 1 minute, $55^{\circ} \mathrm{C}$ for 1 minute, and $68^{\circ} \mathrm{C}$ for 1.5 minutes for APC-B, -C, and -D primer pairs and $94^{\circ} \mathrm{C}$ for 1 minute, $52^{\circ} \mathrm{C}$ for 1 minute, and $68^{\circ} \mathrm{C}$ for 1.5 minutes for APC-A), followed by a final extension at $72^{\circ} \mathrm{C}$ for 10 minutes. For $\beta$-catenin amplification, PCR conditions consisted of an initial denaturation at $95^{\circ} \mathrm{C}$ for 10 minutes, 40 cycles of $94^{\circ} \mathrm{C}$ for 1 minute, $58^{\circ} \mathrm{C}$ for 1 minute, and $72^{\circ} \mathrm{C}$ for 2 minutes, and a final extension at $72^{\circ} \mathrm{C}$ for 10 minutes. For $\mathrm{K}$-ras, PCR reactions were performed with an initial denaturation at $94^{\circ} \mathrm{C}$ for 3 minutes, 40 cycles of $94^{\circ} \mathrm{C}$ for 1 minute, $50^{\circ} \mathrm{C}$ for 1 minute, and $72^{\circ} \mathrm{C}$ for 1 minute, and a final extension at $72^{\circ} \mathrm{C}$ for 7 minutes.

PCR products were cleaned using shrimp alkaline phosphatase and exonuclease I (Amersham, Buckinghamshire, United Kingdom). The products were then sequenced on an ABI Prism 3700 DNA Analyzer (Applied Biosystems) using the ABI Prism Big Dye Terminator Cycle Sequencing Kit (Applied Biosystems). For all three genes, the same primers were used for both amplification and sequencing. Sequencing data were analyzed using GeneScan Analysis software (Applied Biosystems) as per the manufacturer's protocol. Mutations were verified in both forward and reverse directions.

\section{Chromosome 5q Allelic Loss}

Allelic loss on chromosome $5 \mathrm{q}$ was evaluated by microsatellite assays using three microsatellite markers: D5S82, D5S299, and D5S346. Assays were performed by fluorescent-labeled PCR amplification using forward primers labeled with 6-FAM (Applied Biosystems) and unlabeled reverse primers. PCR reactions were performed in $15-\mu \mathrm{L}$ volumes that contained $40 \mathrm{ng}$ of genomic DNA, $9 \mu \mathrm{L}$ of ABI Prism True Allele PCR Premix (Applied Biosystems), 5 pmol of 6-FAM-labeled forward primer, and $10 \mathrm{pmol}$ of unlabeled reverse primer. Cycling conditions consisted of denaturation at $95^{\circ} \mathrm{C}$ for 6 minutes; 45 cycles of $94^{\circ} \mathrm{C}$ for 45 seconds, $55^{\circ} \mathrm{C}$ for 45 seconds, and $72^{\circ} \mathrm{C}$ for 1 minute; and a final extension at $72^{\circ} \mathrm{C}$ for 30 minutes. The PCR products were subsequently diluted with $30 \mu \mathrm{L}$ of $\mathrm{H}_{2} \mathrm{O}$, and a $1.0-\mu \mathrm{L}$ aliquot of each diluted fluorescent-labeled PCR product was combined with $12 \mu \mathrm{L}$ of formamide and 0.5 $\mu \mathrm{L}$ of GeneScan 400HD (ROX) size standard (Applied Biosystems). The samples were then capillary electrophoresed on an ABI 3700 DNA Analyzer and analyzed using GeneScan Analysis software. Allelic loss was defined as a $\geq 50 \%$ reduction in the height of a heterozygous peak as compared with normal control DNA in one or more informative microsatellite markers.

\section{MSI Analysis}

Evaluation for MSI was performed using the five microsatellite loci (D2S123, D5S346, D17S250, Bat25, and Bat-26) recommended by the 1997 National Cancer Institute (NCI)-sponsored consensus conference (33). PCR reaction mixtures and cycling conditions for D2S123, D17S250, Bat-25, and Bat-26 were identical to those described above for $5 \mathrm{q}$ allelic loss (already including D5S346). Primer sequences and interpretation of the chromatograms were in accordance with those previously described in detail by Berg et al. (34). High-level MSI was defined as shifts in at least two of five microsatellite loci ( $\geq 40 \%$ ); low-level MSI as a shift in only one locus (20\%); and microsatellite stable, as when none of the loci were shifted, as per the NCI criteria (33).

\section{Statistical Analysis}

Fisher's exact test was used to evaluate differences in the frequencies of genetic alterations among intestinal-type and gastric-type adenomas. Two-tailed $P$ values of $<.05$ were considered statistically significant.

\section{RESULTS}

The histopathologic and molecular findings in the 18 gastric adenomas are summarized in Table 1.

\section{Intestinal-Type Adenomas}

The 11 intestinal-type adenomas occurred in 6 females and 5 males with a mean age of 75.5 years (range, 62-93 years). As previously described (8), histologic evaluation of the surrounding gastric mucosa revealed that these adenomas arose in the setting of intestinal metaplasia, including extensive antral-predominant intestinal metaplasia in eight patients, extensive corpus-predominant intestinal metaplasia (i.e., autoimmune gastritis) in two patients, and focal intestinal metaplasia only in one patient. In 10 patients, the polyps were endoscopically or surgically resected and examined in their entirety, whereas in the remaining patient the lesion was biopsied only. Polyp size in these 10 re- 
TABLE 1. Genetic Alterations in Intestinal-Type and Foveolar-Type Gastric Adenomas

\begin{tabular}{|c|c|c|c|c|c|c|c|c|}
\hline Case & $\begin{array}{l}\text { Adenoma } \\
\text { Type }\end{array}$ & $\begin{array}{l}\text { Grade of } \\
\text { Dysplasia }\end{array}$ & $\beta$-catenin & $A P C$ & $\begin{array}{l}\text { 5q Allelic } \\
\text { loss }\end{array}$ & K-ras & $\begin{array}{c}\text { MSI } \\
\text { Status }\end{array}$ & Markers Shifted \\
\hline IA-1 & Intestinal & Low & Wild-type & R1450X & + & Wild-type & Stable & - \\
\hline IA-2 & Intestinal & Low & Wild-type & 1554-1556FS (del A) & $\mathrm{N} / \mathrm{I}$ & Wild-type & Stable & - \\
\hline IA-3 & Intestinal & Low & Wild-type & 1554-1556FS (ins A) & $\mathrm{N} / \mathrm{I}$ & Wild-type & Stable & - \\
\hline IA-4 & Intestinal & Low & Wild-type & 1554-1556FS (ins A) & - & G13C & Stable & - \\
\hline IA-5 & Intestinal & High & Wild-type & E1554X & - & Wild-type & Stable & - \\
\hline IA-6 & Intestinal & High & Wild-type & Wild-type & + & G12S & Stable & - \\
\hline IA-7 & Intestinal & High & Wild-type & Wild-type & + & Wild-type & Stable & - \\
\hline IA-8 & Intestinal & High & Wild-type & Wild-type & - & Wild-type & MSI-high & $\begin{array}{l}\text { Bat-25, Bat-26, D2S123, D17S250, } \\
\text { D5S82 }\end{array}$ \\
\hline IA-9 & Intestinal & High & Wild-type & Wild-type & - & Wild-type & MSI-high & $\begin{array}{l}\text { Bat-25, Bat-26, D2S123, D17S250, } \\
\text { D5S346, D5S82, D5S299 }\end{array}$ \\
\hline IA-10 & Intestinal & Low & Wild-type & Wild-type & - & Wild-type & MSI-high & $\begin{array}{l}\text { Bat-25, Bat-26, D5S346, D5S82, } \\
\text { D5S299 }\end{array}$ \\
\hline IA-11 & Intestinal & High & Wild-type & Wild-type & - & Wild-type & Stable & - \\
\hline FA-1 & Foveolar & Low & Wild-type & 1463-1465FS (del AG) & - & G12R & Stable & - \\
\hline FA-2 & Foveolar & Low & Wild-type & N/A & + & Wild-type & Stable & - \\
\hline FA-3 & Foveolar & Low & $\mathrm{N} / \mathrm{A}$ & N/A & + & N/A & Stable & - \\
\hline FA-4 & Foveolar & Low & Wild-type & Wild-type & - & Wild-type & Stable & - \\
\hline FA-5 & Foveolar & Low & Wild-type & Wild-type & - & Wild-type & Stable & - \\
\hline FA-6 & Foveolar & Low & Wild-type & Wild-type & - & Wild-type & Stable & - \\
\hline FA-7 & Foveolar & Low & Wild-type & Wild-type & - & Wild-type & Stable & - \\
\hline
\end{tabular}

corded cases ranged from $0.3-3 \mathrm{~cm}$, with a mean of $1.35 \mathrm{~cm}$. The degree of epithelial dysplasia was classified as low grade in 6 adenomas and as high grade in 5 adenomas. In addition, 2 of the adenomas with high-grade dysplasia contained foci of intramucosal carcinoma, but for the purposes of this study only the adenoma precursors were microdissected and analyzed.

Alterations in the $A P C$ tumor-suppressor gene were the most common genetic alteration identified in intestinal-type adenomas. APC mutations were present in 5 of $11(45.5 \%)$ cases and $5 q$ allelic loss in 3 of 9 (33.3\%) informative cases. The APC mutations included two stop-codon mutations and three frameshift (insertion or deletion) mutations, and therefore all would be expected to result in APC protein truncation. In one of the adenomas, biallelic inactivation of $A P C$ (truncating mutation plus loss of the normal allele) could be demonstrated.

MSI was present in 3 of 11 (27.3\%) intestinal-type adenomas and constituted high-level MSI in all 3 cases (Fig. 3). Among the adenomas studied here, the presence of MSI and APC alterations (mutation and/or allelic loss) appeared to be mutually exclusive. Overall, therefore, 10 of 11 (90.9\%) intestinaltype adenomas demonstrated either $A P C$ alterations or MSI, but not both. Notably, neither MSI nor $A P C$ alterations correlated with adenoma size or degree of dysplasia (Table 1); the only adenoma in this group that did not demonstrate either MSI or $A P C$ alteration was a 1.4 -cm polyp (thus approximating the mean size among the group of intestinal-type adenomas) with high-grade dysplasia and intramucosal carcinoma.
In contrast to the relative frequency of $A P C$ alterations in intestinal-type adenomas, $K$-ras oncogene mutations were present in only two (18.2\%) cases, representing activating codon 12 and codon 13 missense mutations, respectively (Fig. 4). Both of these $K$-ras mutations occurred in adenomas that also contained APC alterations. No $\beta$-catenin mutations were identified, either among adenomas with or without $A P C$ mutations.

\section{Foveolar-Type Adenomas}

The seven foveolar-type adenomas occurred in four females and three males who had a mean age of 65.9 years (range, 54-80 y). Foveolar-type adenomas were in general smaller lesions than intestinal-type adenomas, with a mean size of 0.5 $\mathrm{cm}$ (range, $0.3-1 \mathrm{~cm}$ ). As was described elsewhere (8), in contrast to intestinal-type adenomas, these foveolar-type adenomas were most frequently associated with a nonatrophic and nonintestinalized mucosal background. In only one case (FA-1) was there any metaplasia or atrophy of the surrounding mucosa, a patient with autoimmune gastritis, extensive associated pseudopyloric metaplasia of the gastric body/fundus, and a 1-cm foveolar-type adenoma in the fundus. Epithelial dysplasia was low grade only in all of the foveolar-type adenomas, and none harbored intramucosal or invasive carcinoma.

Alterations in $A P C$ were present in three of seven (42.9\%) foveolar-type adenomas, including two adenomas with $5 q$ allelic loss (Fig. 5) and one adenoma with an intragenic $A P C$ mutation (Fig. 6). This latter adenoma, FA-1, was the 1-cm fundus polyp in 
IA9 Normal
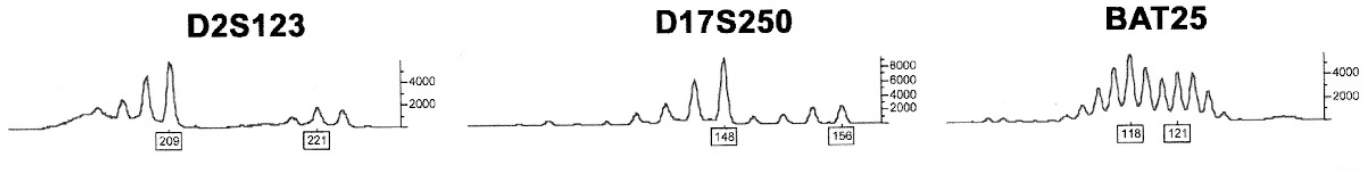

IA9 Polyp
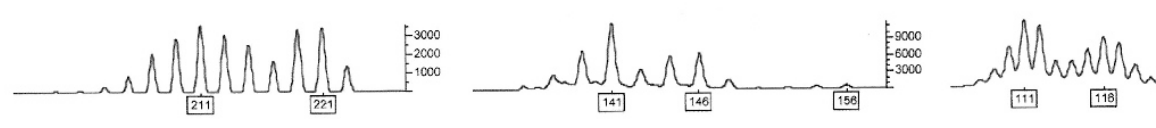

FIGURE 3. High-level microsatellite instability in an intestinal-type adenoma. Representative allelic shifts in D2S123, D17S250, and Bat-25 are illustrated (Case IA-9).

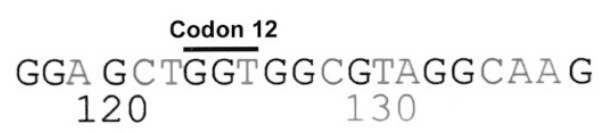

Wild Type
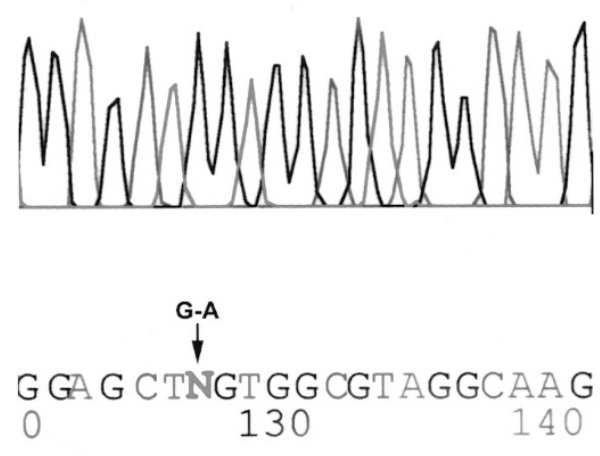

IA6

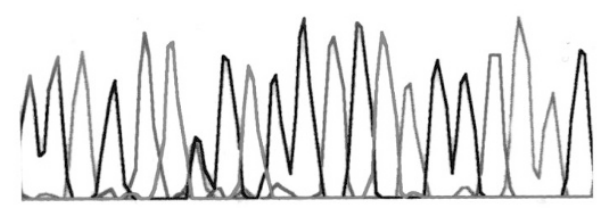

FIGURE 4. K-ras oncogene mutation in an intestinal-type adenoma. A codon 12 GGT(glycine) $\rightarrow$ AGT(serine) mutation is present (Case IA6). The wild-type (normal) mucosa at top shows only the normal GGT DNA sequence at codon 12 of $K$-ras, whereas the intestinal-type adenoma at bottom contains a $\mathrm{G}$ (black peak) to A (green peak) point mutation that will result in the substitution of serine for glycine in the K-ras protein. The sequencing chromatogram for IA-6 shows overlap of the green and black peaks, reflecting the dominant positive nature of the mutation and its presence in only one of the K-ras alleles.

the patient with autoimmune gastritis, representing the only foveolar-type adenoma to arise in association with background mucosal atrophy; it harbored a 2-bp deletion frameshift mutation that would be expected to result in protein truncation. This adenoma also harbored an activating codon 12 $K$-ras mutation; the other five foveolar-type adenomas in which $K$-ras sequencing was completed contained only wild-type sequences. All seven foveolartype adenomas were microsatellite stable. Only wild-type $\beta$-catenin sequences were present in six amplifiable cases.

Foveolar-type adenomas demonstrated a lower overall frequency of detectable clonal genetic alter- ations than did intestinal-type adenomas (i.e., 10 of 11 intestinal-type adenomas contained alterations in APC, $K$-ras, or MSI versus only 3 of 7 foveolartype adenomas; $P=.047$ ). However, there were no particular statistically significant differences between gastric-type and intestinal-type adenomas with respect to alterations in $A P C, K$-ras, or $\beta$-catenin, or with respect to the presence of MSI.

\section{DISCUSSION}

Unlike colorectal carcinogenesis, the adenomacarcinoma sequence is an uncommon pathway for gastric adenocarcinoma development, and most intestinal-type gastric carcinomas do not appear to arise from adenoma precursors $(13,15,35,36)$. Not only do most intestinal-type gastric carcinomas lack an identifiable adenoma precursor histologically, but divergent patterns of allelic loss $(35,36)$ and molecular alterations in genes including $A P C$ $(13,15)$ exist between most adenomas and most carcinomas. Nevertheless, that gastric adenomas can serve as the direct precursors to adenocarcinoma is well documented. Estimations of the frequency of such neoplastic progression have ranged widely in the literature, from $2.5 \%$ to $>50 \%(2-7)$.

We recently reported that $15 \%$ of gastric adenomas examined at The Johns Hopkins Hospital over a 16-year period contained either intramucosal $(7 \%)$ or infiltrating $(8 \%)$ carcinoma (8). However, there was a striking difference between adenomas with an intestinal-type phenotype and those with a foveolar phenotype. Whereas $23 \%$ of intestinal-type adenomas harbored carcinoma, none of the foveolar-type adenomas did (8). The foveolar-type adenomas in that study occurred in two distinct scenarios: FAP associated (in the majority of cases) and sporadic. The fact that foveolar-type adenomas rarely undergo neoplastic progression is further reinforced by epidemiologic evidence, which has failed to show a statistically significantly increased risk of gastric carcinoma among Western patients with FAP, despite the increased incidence of gastric adenomas in these patients (37). We therefore hypothesized that there might be different genetic alterations in foveolar-type and intestinal-type ad- 

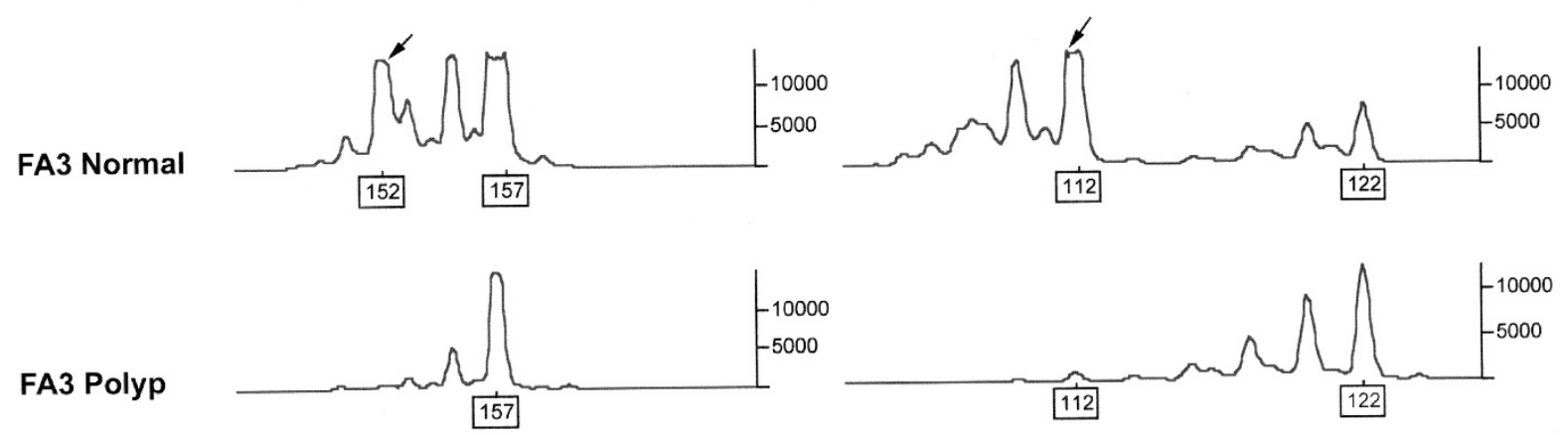

FIGURE 5. Chromosome $5 \mathrm{q}$ allelic loss in a foveolar-type adenoma. Loss of the shorter alleles (arrows) is seen for both microsatellite markers D5S299 and D5S346 (Case FA-3).
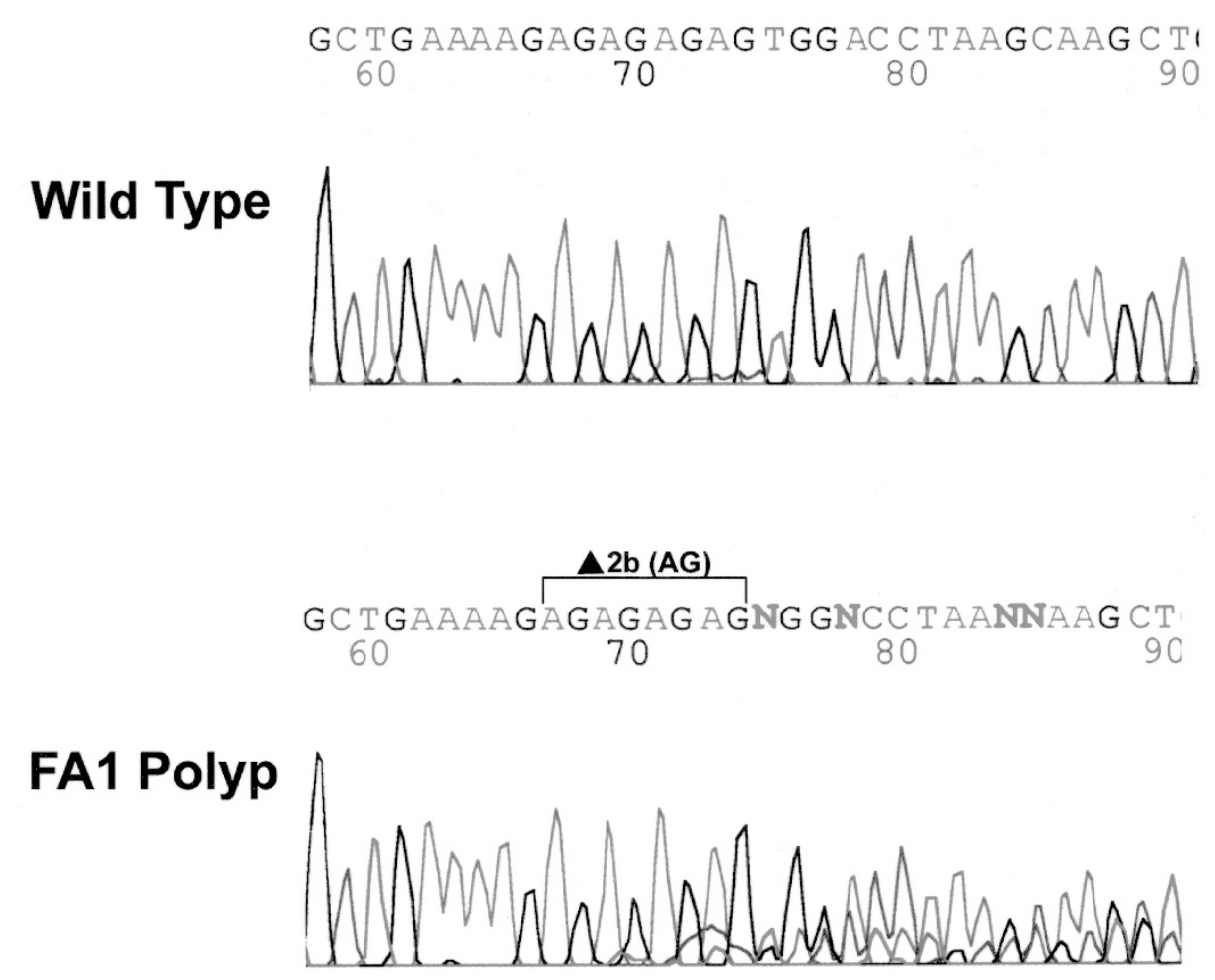

FIGURE 6. Frameshift $A P C$ gene mutation in a foveolar-type adenoma. Sequencing chromatogram shows a 2-bp (AG) deletion in a tract spanning codons 1463-1465 (Case FA-1). The wild-type (normal) mucosa at top shows the expected DNA sequence for this portion of exon 15 of the $A P C$ gene. In the FA-1 polyp at bottom, the DNA sequencing chromatogram shows overlapping bases after the AG deletion because the wild-type and mutated alleles are of different lengths.

enomas to account for this divergent biologic behavior.

We found that intestinal-type adenomas were more likely than foveolar-type adenomas to harbor a detectable clonal genetic alteration in APC, MSI, and/ or $K$-ras ( $91 \%$ versus $43 \%$, respectively). In particular, 5 of 11 intestinal-type adenomas had truncating $A P C$ mutations, but only 1 of 5 amplifiable foveolar-type adenomas did. In addition, 3 of 11 intestinal-type adenomas showed high-level MSI, but all 7 foveolar-type adenomas were microsatellite stable. Furthermore, differences in adenoma size did not account for the presence or absence of
APC mutations or MSI. However, despite the higher frequency of detectable genetic alterations in intestinal-type versus foveolar-type adenomas, no particular alteration (i.e., truncating $A P C$ mutation, $5 \mathrm{q}$ allelic loss, MSI, or K-ras mutation) reached statistical significance. This may be due to the relatively low number of foveolar-type adenomas available for study, because sporadic foveolar-type adenomas are very uncommon lesions.

Previous studies of genetic alterations in $A P C$, $K$-ras, and MSI in gastric adenomas have not generally specified the epithelial phenotype of the adenomas; however, because the vast majority of 
non-FAP-associated gastric adenomas arise in the setting of background intestinal metaplasia and show at least focal intestinal-type differentiation, it is likely that the genetic changes reported in these previous studies reflect mainly those seen in intestinal-type adenomas. Only two prior investigations of $A P C$ in polypoid gastric adenomas have been reported and have shown mutation frequencies of $20 \%$ (6 of 30 adenomas from Japanese patients; 14) and 78\% (25 of 32 adenomas from Korean patients; 15), respectively. In neither study did degree of dysplasia or adenoma size correlate with the presence of $A P C$ mutations, suggesting that, as in the colorectum, $A P C$ alterations are early neoplastic events. The lack of correlation that we also observed between $A P C$ alterations and adenoma size or dysplasia grade in this study also supports this. Interestingly, unlike colorectal adenocarcinomas, which arise predominantly from adenoma precursors and typically harbor truncating $A P C$ mutations, only a minority of differentiated gastric adenocarcinomas contain $A P C$ mutations $(13,15,38)$, an observation suggesting that most gastric adenocarcinomas do not arise from adenoma precursors. Lee et al. (15), for example, found somatic $A P C$ mutations in only $6 \%$ of gastric adenocarcinomas and hypothesized that dysplastic or adenomatous lesions with $A P C$ mutations were actually less likely to progress to carcinoma. In the current study, neither of the two gastric adenomas that harbored adenocarcinoma (intramucosal carcinoma in both) contained detectable APC mutations or $5 q$ allelic loss.

Among colorectal neoplasms that lack detectable $A P C$ mutations, two alternative genetic alterations may be found- $\beta$-catenin oncogene mutations and MSI. Mutations that disrupt phosphorylation sites involved in regulating normal $\beta$-catenin protein degradation can substitute for $A P C$ mutations and theoretically should stimulate similar downstream targets of the $A P C / \beta$-catenin pathway, including transcriptional activation of cyclin DI and c-myc (39-41). Approximately half of colonic adenomas lacking $A P C$ alterations instead harbor stabilizing $\beta$-catenin mutations (42). Notably, $\beta$-catenin mutations are more prevalent among small adenomas than larger adenomas or colonic adenocarcinomas $(43,44)$. This latter observation led us to hypothesize that $\beta$-catenin mutations might be present in gastric adenomas without $A P C$ alterations, particularly the small, foveolar-type adenomas. However, none of the 17 gastric adenomas sequenced here for $\beta$-catenin contained mutations. Only one previous study has evaluated for $\beta$-catenin mutations in gastric adenomas, and similarly reported no $\beta$-catenin mutations among 12 (intestinal-type) adenomas from Korean patients (15). $\beta$-catenin also does not appear to be a frequent mutational target in gastric carcinomas, having been reported in only $0-7.5 \%$ of cases studied (45-50).
A second pathway, MSI, was present in 3 of 11 (27.2\%) intestinal-type adenomas, all of which were MSI high. Several previous studies have reported prevalences of MSI in gastric adenomas ranging from $8 \%$ to $28.6 \%(15,23,24,26,27)$, with the majority of MSI-high cases associated with decreased hMLH1 expression due to hypermethylation of the $h M L H 1$ gene promoter, as occurs in sporadic microsatelliteunstable colorectal neoplasms (26). One recent study of gastric carcinomas identified MSI by Bat-25/Bat-26 analysis in only $8 \%$ of intestinal-type carcinomas but in $57 \%$ of carcinomas with a foveolar phenotype (foveolar-type carcinomas expressing gastric mucins; 51). We therefore hypothesized that foveolar-type adenomas might also have a high frequency of MSI. However, all seven foveolar-type adenomas evaluated here were microsatellite stable, further suggesting a different molecular pathogenesis between foveolartype adenomas and foveolar-type adenocarcinomas.

Among colorectal neoplasms, both $A P C / \beta$ catenin pathway alterations and MSI represent early neoplastic events, whereas $K$-ras oncogene mutations and $p 53$ tumor suppressor gene mutations are secondary, subsequent alterations in the neoplastic pathway. We found codon 12 and 13 K-ras mutations in only 3 of 18 gastric adenomas (16.7\%), a prevalence not significantly different from the range $(0-16 \%)$ in previously studied gastric adenomas (6, 13, 15-18). Isogaki et al. (18) found that the $K$-ras mutational frequency increased with higher degrees of dysplasia in their set of 50 adenomas. Similarly, Tsuchiya et al. 16) found that the $K$-ras mutations present in $10.5 \%$ of their set of 38 adenomas were not homogeneously distributed (i.e., could be present only focally within different sites from the same adenoma). The three $K$-ras mutations detected in the current study were present only in adenomas of $\geq 1 \mathrm{~cm}(1 \mathrm{~cm}, 1.5 \mathrm{~cm}$, and $2 \mathrm{~cm}$ ), supporting that these are secondary genetic events in neoplastic progression.

In summary, the findings in this study suggest that gastric adenomas (particularly those of intestinal phenotype), like colorectal adenomas, arise predominantly through mutational inactivation of the $A P C$ tumor suppressor gene, with MSI representing a less frequent pathway. Adenomas of pure foveolar phenotype are encountered only rarely. They were less likely to harbor detectable clonal genetic alterations than those of intestinal type, although no particular genetic alteration reached statistical significance.

\section{REFERENCES}

1. Stolte M, Sticht T, Eidt S, Ebert D, Finkenzeller G. Frequency, location, and age and sex distribution of various types of gastric polyp. Endoscopy 1994;26:659-65.

2. Kolodziejczyk P, Yao T, Oya M, Nakamura S, Utsunomiya T, Ishikawa T, et al. Long-term follow-up study of patients with 
gastric adenomas with malignant transformation. An immunohistochemical and histochemical analysis. Cancer 1994; 74:2896-907.

3. Laxen F, Sipponen P, Ihamaki T, Hakkiluoto A, Dortscheva Z. Gastric polyps; their morphological and endoscopical characteristics and relation to gastric carcinoma. Acta Pathol Microbiol Immunol Scand [A] 1982;90:221-8.

4. Nakamura K, Sakaguchi H, Enjoji M. Depressed adenoma of the stomach. Cancer 1988;62:2197-202.

5. Orlowska J, Jarosz D, Pachlewski J, Butruk E. Malignant transformation of benign epithelial gastric polyps. Am J Gastroenterol 1995;90:2152-9.

6. Sakurai S, Sano T, Nakajima T. Clinicopathological and molecular biological studies of gastric adenomas with special reference to p53 abnormality. Pathol Int 1995;45:51-7.

7. Stolte M. Clinical consequences of the endoscopic diagnosis of gastric polyps. Endoscopy 1995;27:32-7.

8. Abraham SC, Montgomery EA, Singh VK, Yardley JH, Wu T-T. Gastric adenomas: intestinal-type and gastric-type adenomas differ in the risk of adenocarcinoma and presence of background mucosal pathology. Am J Surg Pathol 2002;26: 1276-85.

9. Tsukashita S, Kushima R, Bamba M, Sugihara H, Hattori T. MUC gene expression and histogenesis of adenocarcinoma of the stomach. Int J Cancer 2001;94:166-70.

10. Wang YZ, Mitomi H, Kurihara M, Ishihara K, Hotta K, Tanigawa $\mathrm{H}$, et al. Gastric adenomas and superficial adenocarcinomas display distinct patterns of mucin carbohydrate and core protein expression. Histopathology 2000;37:250-9.

11. Kushima R, Muller W, Stolte M, Borchard F. Differential p53 protein expression in stomach adenomas of gastric and intestinal phenotypes: possible sequences of p53 alteration in stomach carcinogenesis. Virchows Arch 1996;428:223-7.

12. Snover DC. Benign epithelial polyps of the stomach. Pathol Annu 1985;20 Pt 1:303-29.

13. Maesawa C, Tamura G, Suzuki Y, Ogasawara S, Sakata K, Kashiwaba M, et al. The sequential accumulation of genetic alterations characteristic of the colorectal adenomacarcinoma sequence does not occur between gastric adenoma and adenocarcinoma. J Pathol 1995;176:249-58.

14. Tamura G, Maesawa C, Suzuki Y, Tamada H, Satoh M, Ogasawara S, et al. Mutations of the APC gene occur during early stages of gastric adenoma development. Cancer Res 1994;54: $1149-51$.

15. Lee J-H, Abraham SC, Kim H-S, Nam J-H, Choi C, Lee M-C, et al. Inverse relationship between APC gene mutation in gastric adenomas and development of adenocarcinoma. Am J Pathol 2002;161:611-8.

16. Tsuchiya C, Ohshima S, Takahama M. Detection of c-Ki-ras oncogene mutation in gastric adenomas with formalin-fixed, paraffin-embedded biopsy materials. J Gastroenterol 1997; 32:28-33.

17. Koshiba M, Ogawa O, Habuchi T, Hamazaki S, Shimada T, Takahashi R, et al. Infrequent ras mutation in human stomach cancers. Jpn J Cancer Res 1993;84:163-7.

18. Isogaki J, Shinmura K, Yin W, Arai T, Koda K, Kimura T, et al. Microsatellite instability and K-ras mutations in gastric adenomas, with reference to associated gastric cancers. Cancer Detect Prev 1999;23:204-14.

19. Oya M, Yao T, Tsuneyoshi M. Expressions of cell-cycle regulatory gene products in conventional gastric adenomas: possible immunohistochemical markers of malignant transformation. Hum Pathol 2000;31:279-87.

20. Kyokane K, Ito M, Sato Y, Ina K, Ando T, Kusugami K. Expression of Bcl-2 and p53 correlates with the morphology of gastric neoplasia. J Pathol 1998;184:382-9.

21. Lauwers GY, Wahl SJ, Melamed J, Rojas-Corona RR. p53 expression in precancerous gastric lesions: an immunohistochemical study of PAb 1801 monoclonal antibody on ad- enomatous and hyperplastic gastric polyps. Am J Gastroenterol 1993;88:1916-9.

22. Tohdo H, Yokozaki H, Haruma K, Kajiyama G, Tahara E. p53 gene mutations in gastric adenomas. Virchows Arch 1993; 63:191-5.

23. Tamura G, Sakata K, Maesawa C, Suzuki Y, Terashima M, Satoh $\mathrm{K}$, et al. Microsatellite alterations in adenoma and differentiated adenocarcinoma of the stomach. Cancer Res 1995;55:1933-6.

24. Nogueira AM, Carniero F, Seruca R, Cirnes L, Veiga I, Machado JC, et al. Microsatellite instability in hyperplastic and adenomatous polyps of the stomach. Cancer 1999;86: 1649-56.

25. Fleisher AS, Esteller M, Tamura G, Rashid A, Stine OC, Yin J, et al. Hypermethylation of the hMLH1 gene promoter is associated with microsatellite instability in early human gastric neoplasia. Oncogene 2001;20:329-35.

26. Baek MJ, Kang H, Kim SE, Park JH, Lee JS, Paik YK, et al. Expression of hMLH1 is inactivated in the gastric adenomas with enhanced microsatellite instability. Br J Cancer 2001; 85:1147-52.

27. Kim HS, Woo DK, Bae SI, Kim YI, Kim WH. Microsatellite instability in the adenoma-carcinoma sequence of the stomach. Lab Invest 2000;80:57-64.

28. Semba S, Yokozaki H, Yamamoto S, Yasui W, Tahara E. Microsatellite instability in precancerous lesions and adenocarcinomas of the stomach. Cancer 1996;77:1620-7.

29. Goldstein NS, Lewin KJ. Gastric epithelial dysplasia and adenoma: historical review and histological criteria for grading. Hum Pathol 1997;28:127-33.

30. Lauwers GY. Gastric dysplasia: diagnosis and significance. Pathol Case Rev 2002;7:27-34.

31. Rugge M, Correa P, Dixon MF, et al. Gastric dysplasia. The Padova international classification. Am J Surg Pathol 2000; 24:167-76.

32. Moskaluk CA, Kern SE. Microdissection and polymerase chain reaction amplification of genomic DNA from histological tissue sections. Am J Pathol 1997;150:1547-52.

33. Boland CR, Thibodeau SN, Hamilton SR, Sidransky D, Eshleman JR, Burt RW, et al. A National Cancer Institute Workshop on Microsatellite Instability for cancer detection and familial predisposition: development of international criteria for the determination of microsatellite instability in colorectal cancer. Cancer Res 1998;58:5248-57.

34. Berg KD, Glaser CL, Thompson RE, Hamilton SR, Griffin CA, Eshleman JR. Detection of microsatellite instability by fluorescence multiplex polymerase chain reaction. J Mol Diagn 2000;2:20-8.

35. Tamura G, Sakata K, Nishizuka S, Maesawa C, Suzuki Y, Terashima M, et al. Allelotype of adenoma and differentiated adenocarcinoma of the stomach. J Pathol 1996;180:371-7.

36. Tamura G. Molecular pathogenesis of adenoma and differentiated adenocarcinoma of the stomach. Pathol Int 1996; 46:834-41.

37. Offerhaus GJA, Giardiello FM, Krush A, et al. The risk of upper gastrointestinal cancer in familial adenomatous polyposis. Gastroenterology 1992;102:1980-2.

38. Horii A, Nakatsuru S, Miyoshi Y, Ichii S, Nagase H, Kato Y, et $a l$. The APC gene, responsible for familial adenomatous polyposis, is mutated in human gastric cancer. Cancer Res 1992;52:3231-3.

39. Tetsu O, McCormick F. $\beta$-catenin regulates expression of cyclin D1 in colon carcinoma cells. Nature 1999;398:422-6.

40. Mann B, Gelos M, Siedow A, Hanski ML, Gratchev A, Ilyas M, et al. Target genes of $\beta$-catenin-T cell-factor/lymphoidenhancer-factor signaling in human colorectal carcinomas. Proc Natl Acad Sci U S A 1999;96:1603-8. 
41. Sellin JH, Umar S, Xiao J, Morris AP. Increased $\beta$-catenin expression and nuclear translocation accompany cellular hyperproliferation in vivo. Cancer Res 2001;61:2899-906.

42. Sparks AB, Morin PJ, Vogelstein B, Kinzler KW. Mutational analysis of the APC/ $\beta$-catenin/Tcf pathway in colorectal cancer. Cancer Res 1998;58:1130-4.

43. Samowitz WS, Powers MD, Spirio LN, Nollet F, van Roy F, Slattery ML. $\beta$-catenin mutations are more frequent in small colorectal adenomas than in larger adenomas and invasive carcinomas. Cancer Res 1999;59:1442-4.

44. Kitaeva MN, Grogan L, Williams JP, Dimond E, Nakahara K, Hausner $\mathrm{P}$, et al. Mutations in $\beta$-catenin are uncommon in colorectal cancer occurring in occasional replication errorpositive tumors. Cancer Res 1997;57:4478-81.

45. Tong JH, To KF, Ng EK, Lau JY, Lee TL, Lo KW, et al. Somatic $\beta$-catenin mutation in gastric carcinoma-an infrequent event that is not specific for microsatellite instability. Cancer Lett 2001;163:125-30.

46. Woo DK, Kim HS, Lee HS, Kang YH, Yang HK, Kim WH. Altered expression and mutation of $\beta$-catenin gene in gastric carcinomas and cell lines. Int J Cancer 2001;95:108-13.
47. Ebert MP, Fei G, Kahmann S, Muller O, Yu J, Sung JJ, et al. Increased $\beta$-catenin mRNA levels and mutational alterations of the APC and $\beta$-catenin gene are present in intestinal-type gastric cancer. Carcinogenesis 2002;23:87-91.

48. Sasaki Y, Morimoto I, Kusano M, Hosokawa M, Itoh F, Yanagihara $\mathrm{K}$, et al. Mutational analysis of the betacatenin gene in gastric carcinomas. Tumour Biol 2001;22: 123-30.

49. Candidus S, Bischoff P, Becker KF, Hofler H. No evidence for mutations in the alpha- and beta-catenin genes in human gastric and breast carcinomas. Cancer Res 1996; 56:49-52.

50. Clements WM, Wang J, Sarnaik A, Kim OJ, MacDonald J, Fenoglio-Preiser C, et al. Beta-catenin mutation is a frequent cause of Wnt pathway activation in gastric cancer. Cancer Res 2002;62:3503-6.

51. Endoh Y, Tamura G, Ajioka Y, Watanabe H, Motoyama T. Frequent hypermethylation of the hMLH1 gene promoter in differentiated-type tumors of the stomach with the gastric foveolar phenotype. Am J Pathol 2000;157:717-22.

\section{Book Review}

\section{Gray W, McKee G: Diagnostic Cytopathology, Second Edition, 1100 pp, city, Churchill Liv- ingstone, 2002 (\$295.00).}

Diagnostic Cytopathology, Second Edition is aimed at practicing and training pathologists as well as screening personnel. The book is easy to read and well organized. Color-coded main topic sections serve as thumb indexes and are coordinated to match the table of contents, making the sections very quick and easy to find. Also useful are the topic and subtopic headings within each chapter. The organization of each chapter remains constant throughout the book, making each subtopic exceptionally easy to find.

There are summaries of "Cytological Findings" at the beginning of each diagnostic entity in a bulleted format for a quick glimpse of the "nitty-gritty" of what one needs to know, followed by an extensive explanation and expansion of each finding. These sections give brief and to-the-point explanations of nuclear features, grouping patterns, cytoplasmic features, and even staining patterns where appropriate. The expansions that follow give more detail and essentially everything one needs to know about a given sample. There are "Cytological Findings" sections not only for each diagnostic entity, but also for many given techniques for that entity. For example, findings in washings are in a sepa- rate section from findings in brushings. This makes for much more specific information and is extremely useful.

The "Cytological Findings" sections are followed by "Diagnostic Pitfalls" sections for each case. These sections are also quite useful, not only for those in training, but for experienced pathologists as well. These sections cover "why it isn't" another entity and answer many questions before they are asked. The "Diagnostic Pitfalls" also give helpful information on the alternative diagnoses as well as suggestions for further testing.

The photomicrographs are plentiful and of excellent quality, with helpful legends and appropriate referencing within the text. The tables throughout the book are invaluable for organizing large amounts of information, and we found them exceptionally easy to follow.

In general, this reviewer is impressed by the Diagnostic Cytopathology, Second Edition and would highly recommend it for practicing pathologists, fellows, and residents as well as screening personnel as a bench reference.

\author{
Barbara Shideler \\ University of Kansas Medical Center \\ Kansas City, Kansas
}

